\title{
Pharmacological treatment of psoriatic arthritis: a systematic literature review for the 2015 update of the EULAR recommendations for the management of psoriatic arthritis
}

\author{
Sofia Ramiro, ${ }^{1}$ Josef S Smolen, ${ }^{2}$ Robert Landewé, ${ }^{3}$ Désirée van der Heijde, ${ }^{1}$ \\ Maxime Dougados, ${ }^{4,5}$ Paul Emery, ${ }^{6,7}$ Maarten de Wit, ${ }^{8}$ Maurizio Cutolo, ${ }^{9}$ \\ Susan Oliver, ${ }^{10}$ Laure Gossec $^{11,12}$
}

\section{Handling editor Francis} Berenbaum

- Additional material is published online only. To view please visit the journal online (http://dx.doi.org/10.1136/ annrheumdis-2015-208466).

For numbered affiliations see end of article.

\section{Correspondence to} Dr Sofia Ramiro, Department of Rheumatology, Leiden University Medical Center, PO Box 9600, 2300RC Leiden, The Netherlands;

sofiaramiro@gmail.com

Received 25 August 2015 Revised 12 October 2015 Accepted 30 October 2015 Published Online First 11 December 2015

CrossMark S Linked

- http://dx.doi.org/10.1136/ annrheumdis-2015-208337

\section{ABSTRACT}

Objective To update the evidence on the efficacy and safety of pharmacological agents in psoriatic arthritis (PsA).

Methods Systematic literature review of randomised controlled trials comparing pharmacological interventions in PsA: non-steroidal anti-inflammatory drugs, glucocorticoid, synthetic disease modifying antirheumatic drugs (sDMARDs) either conventional or targeted, biologicals (bDMARDs), placebo or any combination. Main outcomes were American College of Rheumatology (ACR)20-50, Psoriasis Area Severity Index 75, radiographic progression, and withdrawals due to adverse events (AEs). Multiple studies of the same intervention were meta-analysed using random effects. Results In total, 25 papers and 12 abstracts were included. The efficacy of tumour necrosis factor inhibitors (including the recently added golimumab and certolizumab pegol) was confirmed and 16 articles/ abstracts focused on 3 drugs with new modes of action: ustekinumab (UST), secukinumab (SEC) and apremilast (APR). All were placebo-compared trials and met their primary end point, ACR20. In 2 studies with UST ACR20 was met by $50 \%$ and $44 \%$ of patients with UST $90 \mathrm{mg}$, $42 \%$ and $44 \%$ with UST $45 \mathrm{mg}$ vs $23 \%$ and $20 \%$ with placebo, respectively. In two studies with SEC ACR20 ranged 54\% (SEC $300 \mathrm{mg}$ ), 50-51\% (SEC $150 \mathrm{mg}$ ), 29-51\% (SEC $75 \mathrm{mg}$ ) and 15-17\% (placebo). In four studies with APR, ACR20 ranged 32-43\% (APR $30 \mathrm{mg}$ ), 29-38\% (APR $20 \mathrm{mg}$ ) and 17-20\% (placebo). For all three drugs, no more withdrawals due to AEs than placebo were seen and, in general, safety appeared satisfactory. A strategy trial, Tlght COntrol of Psoriatic Arthritis (TICOPA), showed better ACR responses with treatment adaptations upon tight control compared with standard care.

Conclusions UST, SEC and APR are new drugs with efficacy demonstrated for the treatment of PSA. No major safety signals arise, but long-term studies are needed. This review informed about the European League Against Rheumatism recommendations for management of PsA.

\section{INTRODUCTION}

Pharmacological management of psoriatic arthritis (PsA) is an area that has witnessed an important expansion in the last few years. Initially the management of the disease was based on knowledge that was borrowed from the experience in rheumatoid arthritis (RA). Later on, and mainly since the advent of the biological therapies, trials started to be conducted specifically in patients with PsA, mostly after the same drugs had demonstrated efficacy in RA. However, this situation has recently changed, with randomised controlled trials (RCTs) demonstrating efficacy of new compounds that are not used for the treatment of RA. ${ }^{1-5}$ This provides rheumatologists with new options for the treatment of PsA, which, in turn, calls for the need of updating treatment recommendations. ${ }^{6}$ The European League against Rheumatism (EULAR) developed management recommendations in $2011^{6}$ and an initiative took place in 2014-2015 to update these recommendations.

The objective of the present work was to update the evidence on efficacy and safety of pharmacological agents for the management of patients with PsA through a systematic literature review (SLR) with meta-analysis if possible to inform the task force on the update of the EULAR recommendations for the management of PsA.

\section{METHODS}

The present SLR was performed as an update of the 2011 EULAR SLR ${ }^{8}$ thus only pharmacological non-topical treatments were dealt with, and only data published after 2010 were included.

\section{Search methodology}

The questions were reformulated according to the PICO format (Patients, Interventions, Comparisons and Outcomes) ${ }^{9}$ and the eligible study types were defined. Patients were defined as adults ( $\geq 18$ years old) with a clinical diagnosis of PsA. The intervention was defined as any disease modifying antirheumatic drug (DMARD), either biological (bDMARD) or synthetic (sDMARD), the latter in turn including conventional (csDMARD) and targeted (tsDMARD) sDMARDs; ${ }^{10}$ systemic glucocorticoids; non-steroidal anti-inflammatory drugs (NSAIDs) or any combination of them. The following bDMARDs were included: anakinra, infliximab, etanercept, adalimumab, rituximab, abatacept, tocilizumab, golimumab, 
certolizumab pegol, ustekinumab (UST), secukinumab (SEC), brodalumab, ixekizumab, in all formulations, and duration, as well as biosimilars if data were available. Similarly, all sDMARDs were considered, including csDMARDs previously analysed in PsA: methotrexate (MTX), leflunomide, hydroxychloroquine, sulfasalazine, gold/auranofin, azathioprine, chlorambucil, chloroquine, ciclosporine, cyclophosphamide, mycophenolate, minocycline or penicillamine, but also the tsDMARDs apremilast (APR) and tofacitinib. The comparator was any bDMARD, sDMARD, glucocorticoid, NSAID, combination of any of these or placebo (PBO).

The outcomes were divided into efficacy and safety. For efficacy, we report on the primary outcomes of the respective trials, but focus on the American College of Rheumatology 20\% improvement (ACR20), as this was frequently the primary end point in trials. For safety, the primary outcome was withdrawals due to adverse events (AEs). Secondary efficacy outcomes collected were ACR50, ACR70, Psoriasis Area Severity Index (PASI) 50-70-90, PsA response criteria (PsARC), EULAR good or moderate response, improvement in the 28 -joint count Disease Activity Score or its components (swollen joint count (SJC), tender joint count, patient's global assessment of disease activity, and erythrocyte sedimentation rate or $\mathrm{C}$ reactive protein), minimum disease activity state, ${ }^{11}$ improvement in functional disability, improvement in enthesitis, dactylitis and nail involvement, absenteeism, work productivity, cost-efficacy and structural damage. Secondary safety outcomes were serious AEs (SAEs), serious infections, tuberculosis, candidiasis, malignancies, skin exacerbation and demyelinating disease. Only RCTs published after 2010, either phase III or IV (including long-term extensions) as well as strategy trials were included.

The search was performed in Medline, Embase and The Cochrane Central Register of Controlled Trials (Central), on 17 December 2014, without language restrictions. Abstracts were also obtained from the 2013-2014 EULAR and ACR conferences. If an abstract used for the SLR was published in a manuscript before the present paper was submitted in its final format (5 October 2015), then the data from the manuscript were used. Also, some papers were made available by the authors once in press and this was also taken into account in the references. Details on the complete search strategy are provided in online supplementary text 1 .

\section{Study selection, data collection and assessment of risk of bias}

One reviewer (SR) assessed titles and abstracts for suitability for inclusion in the SLR, according to predetermined inclusion criteria, followed by full-text review, where necessary. Data were extracted on study characteristics, interventions and all the above-mentioned outcomes. Risk of bias (RoB) was assessed according to the Risk of Bias Cochrane tool. ${ }^{12}$

\section{Data analysis}

For all interventions and patient populations for which more than one relevant RCT was identified, a meta-analysis was performed for the following main efficacy outcome measures: ACR20-50-70, PASI75-90 and EULAR response. Only studies that were judged as clinically homogeneous were pooled together. A random-effects model was used to be conservative, independently of the statistical heterogeneity, and analysis was conducted using RevMan. ${ }^{13}$ Risk ratios (RRs) with corresponding 95\% CIs were calculated. Numbers needed to treat (NNT) were calculated for the main efficacy outcomes at the time point of the primary end point of the initial RCT.

\section{RESULTS}

The search yielded 2278 articles, of which 113 were selected for detailed review, and 387 conference abstracts. In the end, 25 full papers and 12 conference abstracts met inclusion criteria (see online supplementary figure S1). Of these, three studies investigated the effect of csDMARDs. ${ }^{14-16}$ In total, 15 papers and 2 abstracts focused on tumour necrosis factor inhibitors (TNFis), mainly the ones for which no data were previously available in $\mathrm{PsA}^{8}$ - golimumab and certolizumab pegol, ${ }^{17-27}$ one study on the combination of infliximab with MTX versus MTX in MTX-naïve patients, ${ }^{28}$ one post hoc analysis with adalimu$\mathrm{mab}^{29}$ and one study compared two etanercept regimens. ${ }^{30-33}$ A substantial part of the new evidence (6 papers and 10 abstracts) addressed the new compounds: UST (bDMARD anti-IL-12/23), SEC (bDMARD, anti-IL-17A) and APR (tsDMARD, inhibitor of phosphodiesterase 4). ${ }^{1-5} \quad 34-43$ One strategy trial was included. ${ }^{44}$ No studies were found on biosimilars, glucocorticoids or NSAIDs (table 1). Details on several efficacy and safety outcomes from each study can be found in the online supplementary tables S1-S8.

\section{Conventional synthetic disease modifying antirheumatic drugs} The Methotrexate In Psoriatic Arthritis (MIPA) trial, ${ }^{14}$ at low RoB, compared MTX $15 \mathrm{mg} /$ week to PBO in DMARD-naive patients. The primary end point, PsARC at 24 weeks, was 1.77 times more likely to be achieved by patients on MTX compared with $\mathrm{PBO}$ (no individual responses per treatment arm reported); however, this difference did not reach statistical significance. ACR responses were not significantly different either; improvements in patients' and physicians' global assessments were higher in the MTX arm (see online supplementary tables S2 and S4).

\section{Tumour necrosis factor inhibitors}

RCTs with golimumab and certolizumab pegol have demonstrated their efficacy and safety with respect to all outcomes in the treatment of PsA, as had already been shown for other TNFis. ${ }^{17-27}$ Interestingly, unlike in other trials of TNFi the certolizumab pegol trial, RAPID-PsA, included patients who were TNFi inadequate responders (TNFi-IR, stratified randomisation), allowing a proper subgroup comparison. ACR responses were similar in TNFi-naive and TNFi-IR patients (see online supplementary table S3), however, only about $20 \%$ of the patients were TNFi-IRs.

There was no trial comparing the start of a TNFi as monotherapy versus the start of a TNFi with MTX. The RESPOND, ${ }^{28}$ at high RoB (not blinded, with recruitment stopping prematurely), comparing the combination of infliximab and MTX with MTX did not provide useful information.

The Psoriasis Randomized Etanercept STudy in Subjects with Psoriatic Arthritis (PRESTA) trial, ${ }^{30-33}$ comparing two regimens of etanercept $(50 \mathrm{mg}$ twice a week vs $50 \mathrm{mg}$ once a week) revealed no differences in joint responses (similar ACR responses), nor in the effect on the entheses, dactylitis or on functional disability, but a higher skin response for the higher dose (PASI75 of $55 \%$ for etanercept twice a week vs $36 \%$ for etanercept once a week).

\section{Therapies against new targets: UST, SEC and APR}

Efficacy and safety aspects of the three new compounds (UST, SEC and APR) are summarised in tables 1 and 2, figures 1-3, online supplementary tables S1-S9 and figures S2 and S3. 
Table 1 Characteristics of the RCTs of pharmacological drugs in PsA published in 2010-2015†

\begin{tabular}{|c|c|c|c|c|c|c|}
\hline Drug and trial acronym & $\begin{array}{l}\text { Number of } \\
\text { publications } \\
\text { (abstracts) }\end{array}$ & Interventions compared & $\begin{array}{l}\text { Type of patients } \\
\text { included }\end{array}$ & $\begin{array}{l}\text { Timing of primary } \\
\text { end point }\end{array}$ & Primary end point & $\begin{array}{l}\text { Risk of bias } \\
\text { assessment }\end{array}$ \\
\hline MTX $(\text { MIPA })^{14}$ & $1(0)$ & MTX 15 m/week, PBO & $\begin{array}{l}\text { DMARD or NSAIDs } \\
\text { failure, but MTX } \\
\text { naive }\end{array}$ & $24 \mathrm{~W}$ & PSARC & Low \\
\hline MTX vs Ciclosporine ${ }^{15}$ & $1(0)$ & $\mathrm{ETA}+\mathrm{MTX}, \mathrm{ETA}+\mathrm{CYC}$ & DMARD failure & $24 \mathrm{~W}$ & NA & Unclear \\
\hline Leflunomide $^{16}$ & $1(0)$ & LEF, MTX & NA & $24 \mathrm{~W}$ & PsARC & High \\
\hline $\begin{array}{l}\text { Golimumab } \\
\text { (GO-REVEAL) }^{17-21}\end{array}$ & $5(0)$ & $\begin{array}{l}\text { GOL } 100 \mathrm{mg}, \mathrm{GOL} \\
50 \mathrm{mg}, \mathrm{PBO}\end{array}$ & $\begin{array}{l}\text { DMARD or NSAIDs } \\
\text { failure }\end{array}$ & $\begin{array}{l}14 \mathrm{~W}+24 \mathrm{~W} \\
\text { (coprimary end } \\
\text { point) }\end{array}$ & $\begin{array}{l}\text { ACR20+change in } \\
\text { radiographic score }\end{array}$ & Low \\
\hline $\begin{array}{l}\text { Certolizumab pegol } \\
\text { (RAPID-PsA) }\end{array}$ & $4(2)$ & $\begin{array}{l}\text { CZP } 400 \mathrm{mg}, \text { CZP } \\
200 \mathrm{mg}, \text { PBO }\end{array}$ & $\begin{array}{l}\text { DMARD or TNFi } \\
\text { failure }\end{array}$ & $12 \mathrm{~W}$ & ACR20 & Low \\
\hline Infliximab (RESPOND) ${ }^{28}$ & $1(0)$ & $\begin{array}{l}\text { IFX } 5 \mathrm{mg} / \mathrm{kg}+\mathrm{MTX} \\
15 \mathrm{mg}, \mathrm{MTX} 15 \mathrm{mg}\end{array}$ & $\begin{array}{l}\text { DMARD or NSAIDs } \\
\text { failure, but MTX } \\
\text { naive }\end{array}$ & $16 \mathrm{~W}$ & ACR20 & High \\
\hline Adalimumab (ADEPT) ${ }^{29}$ & $1(0)$ & ADA $40 \mathrm{mg}$, PBO & NSAIDs failure & $\begin{array}{l}12 \mathrm{~W}+24 \mathrm{~W} \\
\text { (coprimary end } \\
\text { point) }\end{array}$ & $\begin{array}{l}\text { ACR20+change in } \\
\text { radiographic score }\end{array}$ & Unclear \\
\hline $\begin{array}{l}\text { Etanercept } \\
\text { (PRESTA) }^{30} 313233\end{array}$ & $4(0)$ & $\begin{array}{l}\text { ETA } 50 \text { mg } 2 \times \text { week, ETA } \\
50 \mathrm{mg} 1 \times \text { week }\end{array}$ & $\begin{array}{l}\text { DMARD or NSAIDs } \\
\text { failure }\end{array}$ & $12 \mathrm{~W}$ & $\begin{array}{l}\text { Physician's global } \\
\text { assessment of psoriasis }\end{array}$ & Low \\
\hline \multicolumn{7}{|l|}{ UST } \\
\hline -PSUMMIT $1^{145}$ & $1(1)$ & $\begin{array}{l}\text { UST } 90 \text { mg, UST } 45 \text { mg, } \\
\text { PBO }\end{array}$ & $\begin{array}{l}\text { DMARD or NSAIDs } \\
\text { failure }\end{array}$ & $24 \mathrm{~W}$ & ACR20 & Low \\
\hline —PSUMMIT $2^{234}$ & $2(0)$ & & $\begin{array}{l}\text { DMARD or NSAIDs or } \\
\text { TNFi failure }\end{array}$ & $24 \mathrm{~W}$ & ACR20 & Low \\
\hline \multicolumn{7}{|l|}{ SEC } \\
\hline -FUTURE $1^{5}$ & $1(0)$ & $\begin{array}{l}\text { SEC } 150 \mathrm{mg} \text {, SEC } 75 \mathrm{mg}, \\
\text { PBO }\end{array}$ & $\begin{array}{l}\text { DMARD or NSAIDs or } \\
\text { TNFi failure }\end{array}$ & $24 \mathrm{~W}$ & ACR20 & Low \\
\hline -FUTURE $2^{4}$ & $1(0)$ & $\begin{array}{l}\text { SEC } 300 \text { mg, SEC } \\
150 \text { mg, SEC } 75 \text { mg, PBO }\end{array}$ & $\begin{array}{l}\text { DMARD or NSAIDs or } \\
\text { TNFi failure }\end{array}$ & $24 W$ & ACR20 & Low \\
\hline \multicolumn{7}{|l|}{ APR } \\
\hline -PALACE $1^{35-37}$ & $1(3)$ & $\begin{array}{l}\text { APR } 30 \mathrm{mg} \text {, APR } 20 \mathrm{mg} \text {, } \\
\text { PBO }\end{array}$ & $\begin{array}{l}\text { DMARD or TNFi } \\
\text { failure }(<10 \%)\end{array}$ & $16 \mathrm{~W}$ & ACR20 & Unclear \\
\hline -PALACE $2^{38}$ & $0(1)$ & & $\begin{array}{l}\text { DMARD or TNFi } \\
\text { failure }\end{array}$ & $16 \mathrm{~W}$ & ACR20 & $N A^{*}$ \\
\hline -PALACE $3^{39}$ & $0(1)$ & & $\begin{array}{l}\text { DMARD or TNFi } \\
\text { failure }\end{array}$ & $16 \mathrm{~W}$ & ACR20 & $N A^{*}$ \\
\hline -PALACE $4^{40-43}$ & $0(4)$ & & $\begin{array}{l}\text { DMARD or TNFi } \\
\text { failure }\end{array}$ & $16 \mathrm{~W}$ & ACR20 & $N A^{*}$ \\
\hline Strategy trial $(\mathrm{TICOPA})^{44}$ & $1(0)$ & $\begin{array}{l}\text { Tight control, standard } \\
\text { care }\end{array}$ & DMARD naive & $48 \mathrm{~W}$ & ACR20 & Low \\
\hline
\end{tabular}

No trials were available for glucocorticoids or non-steroidal anti-inflammatory drugs (NSAIDs).

†25 publications and 12 abstracts have been included.

ACR20, American College of Rheumatology 20\% improvement; ADA, adalimumab; ADEPT, adalimumab effectiveness in psoriatic arthritis trial; APR, apremilast; CYC, ciclosporine; CZP, certolizumab pegol; DMARD, disease-modifying antirheumatic drug; ETA, etanercept; GOL, golimumab; IFX, infliximab; LEF, leflunomide; MIPA, methotrexate in psoriatic arthritis; MTX, methotrexate; NA* , not assessed, risk of bias assessment not possible as only abstract data; NA, not available; NSAID, non-steroidal anti-inflammatory drug; PALACE, psoriatic arthritis long-term assessment of clinical efficacy; PBO, placebo; PRESTA, psoriasis randomized etanercept study in subjects with psoriatic arthritis; PsA, psoriatic arthritis; PsARC, PsA response criteria; RCTs, randomised controlled trials; SEC, secukinumab; TICOPA, tight control of psoriatic arthritis; TNFi, tumour necrosis factor inhibitor; UST, ustekinumab.

UST RCTs (PSUMMIT-1 and PSUMMIT-2), ${ }^{1} 234$ at low RoB, met their primary end point, ACR20 at 24 weeks. Main efficacy and safety outcomes can be found in table 2, including the NNT. For ACR50, the NNT compared with PBO was 5.2 for UST90 $\mathrm{mg}$ and 6.2 for UST45 $\mathrm{mg}$ in PSUMMIT-1. PSUMMIT-2 included 58\% of TNFi-IR, and NNTs for ACR50 were 6.2 for UST90 $\mathrm{mg}$ and 9.3 for UST45 mg. UST also showed good skin responses, improvement in functional disability and structural damage inhibition. Treatment responses were independent of comedication with MTX and occurred in TNFi-naive and TNFi-experienced patients, but with a numerically better response in the former group. Pooling both studies together, the RRs for ACR20 versus PBO were 2.17 (95\% CI 1.71 to 2.76 ) and 1.95 (95\% CI 1.52 to 2.50 ) for UST90 mg and UST45 mg, respectively (figure 1). Less patients on UST had enthesitis or dactylitis at 24 weeks when compared with PBO. There were not more withdrawals due to AEs or serious infections with UST compared with PBO.

For SEC, two trials have been conducted (FUTURE-1 and FUTURE-2), ${ }^{4} 5$ both meeting their primary end points, ACR20 at 24 weeks, and both at low RoB. The NNT for ACR50 was 3.6 for SEC300 mg in FUTURE-2 and ranged 3.6-3.7 for SEC150 mg and 4.3-9.0 for SEC75 mg (table 2). Treatment responses to SEC were independent of comedication with MTX and were confirmed in TNFi-naive and TNFi-experienced patients, but with a numerically lower response in the latter group. SEC also showed good responses regarding the skin as well as on resolution of enthesitis and dactylitis, improvement 


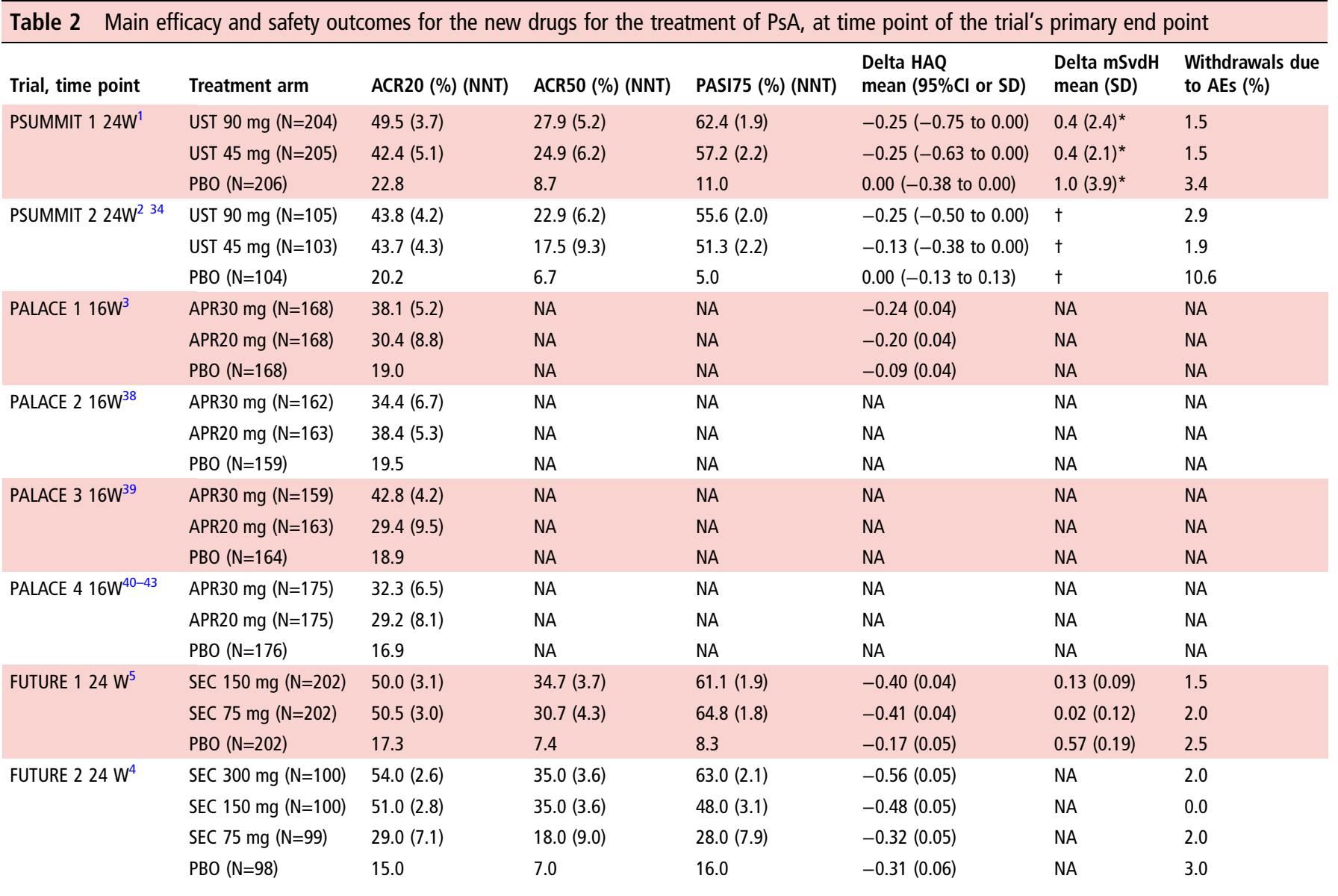

${ }^{*}$ Results reflect a pooled analysis of PSUMMIT 1 and 2, as a priori predefined.

tSee results for PSUMMIT 1 which reflect a pooled analysis of PSUMMIT 1 and 2, as a priori predefined.

ACR20: American College of Rheumatology $20 \%$ improvement; AE, adverse event; APR, apremilast; HAQ, health assessment questionnaire; mSvDH, modified Sharp-van der Heijde score; NA, not available; NNT, number needed to treat; PALACE, psoriatic arthritis long-term assessment of clinical efficacy; PASI, psoriatic arthritis skin index; PBO, placebo; SEC, secukinumab; UST, ustekinumab.

of functional impairment and structural damage inhibition. Meta-analysis across trials resulted in RRs for ACR20 vs PBO of 3.31 (2.04 to 5.36) for SEC300 mg, 5.82 (1.56 to 21.71) for SEC150 mg and 4.47 (0.66 to 30.26) for SEC75 mg (figure 2). Regarding safety, there were no differences in withdrawals due to AEs or serious AEs (SAEs) in SEC compared with PBO. Of note, there were some cases of candidiasis with SEC $(2 \%$ in FUTURE-1 and 5\% in FUTURE-2, both with SEC $150 \mathrm{mg}$ ), though not leading to more withdrawals, and no case was observed with PBO.

Four trials have been conducted with APR (PALACE $1-4),{ }^{3}{ }^{35-43}$ but only one had been published as a full paper at the time of the present review (psoriatic arthritis long-term assessment of clinical efficacy; PALACE-1). ${ }^{3}$ In PALACE-1, RoB was considered 'unclear' (due to presenting per protocol analyses and no intention-to-treat analysis, unclear sequence generation and allocation concealment). This trial met its primary end point, ACR20 at 16 weeks. For ACR20 NNTs from the four trials ranged 4.2-6.7 for APR30 mg and 5.3-9.5 for APR2 $0 \mathrm{mg}$, both versus PBO (table 2). Meta-analysis resulted in RRs for APR30 mg and APR20 mg versus PBO of 1.98 (1.64 to 2.38 ) and 1.70 (1.40 to 2.06), respectively (figure 3). APR showed skin response, improvement in functional disability and reduction of enthesitis, compared with $\mathrm{PBO}$, but no significant effect on dactylitis. None of the four trials has included data on structural damage. Regarding safety, there were numerically slightly more withdrawals due to AEs (eg, 7.1\% with APR30 mg, 6\% with APR20 mg vs 4.8\% PBO in PALACE-1), but there were no differences in SAEs. Up to $19 \%$ of the patients on APR developed diarrhoea, which occurred early after treatment start and was usually self-limited.

For the three new compounds, no signals on higher malignancy rates compared with $\mathrm{PBO}$ were identified.

\section{Treatment strategies}

TIght COntrol of Psoriatic Arthritis (TICOPA) is the first strategy trial in PsA. ${ }^{44}$ A tight control strategy was compared with standard care. In the tight control arm, patients were started on MTX with rapid escalation to $25 \mathrm{mg}$ and, when the target minimum disease activity was not achieved, treatment was escalated to combination DMARDs and later TNFi, if necessary. The primary end point, ACR20 at 48 weeks, was met showing superiority of tight control $(62 \%$ vs $45 \%)$. The same was true for ACR50-70 responses and PASI75. There were no differences in radiographic progression between the groups, with overall low damage progression in both groups. Patients under tight control had a higher incidence of SAEs (14\% patients with SAEs in tight control and 6\% in standard care), but no unexpected AEs were observed (half of these events were infections). By week $48,26 \%$ of the patients in the tight control arm were still on MTX monotherapy (which was 
A

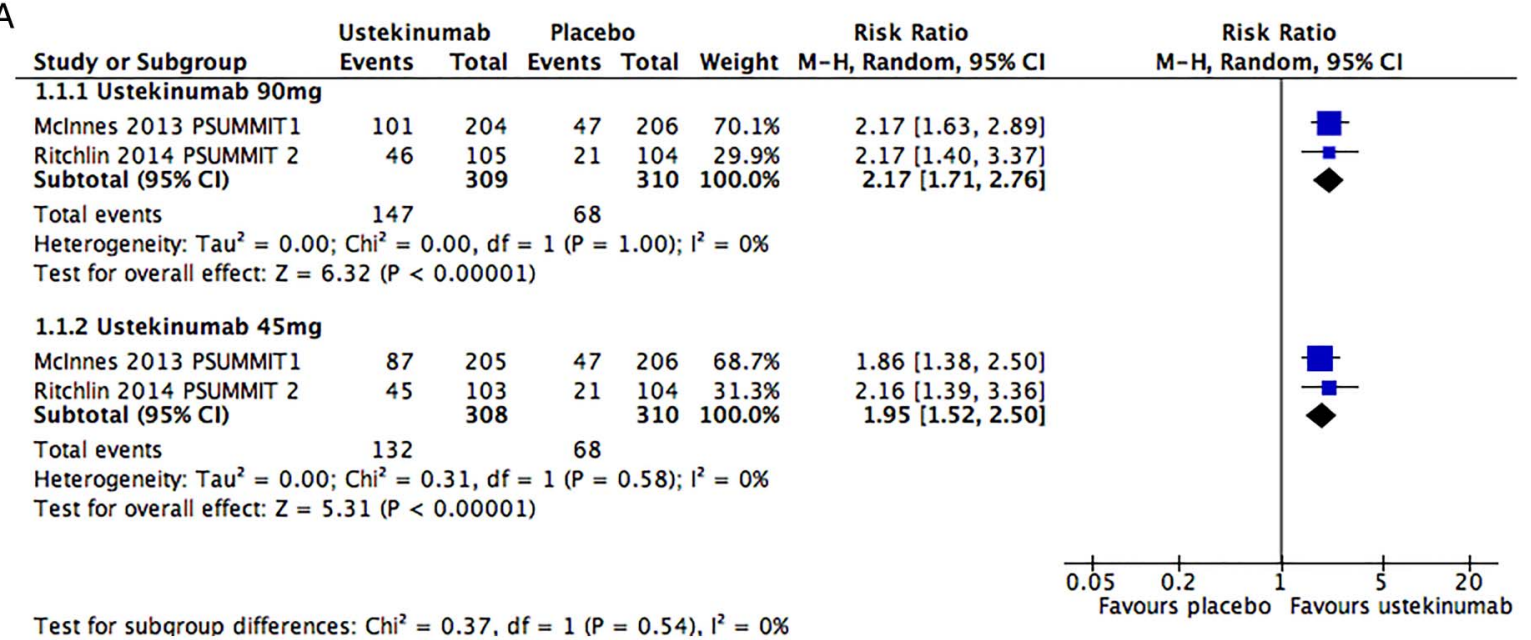

B

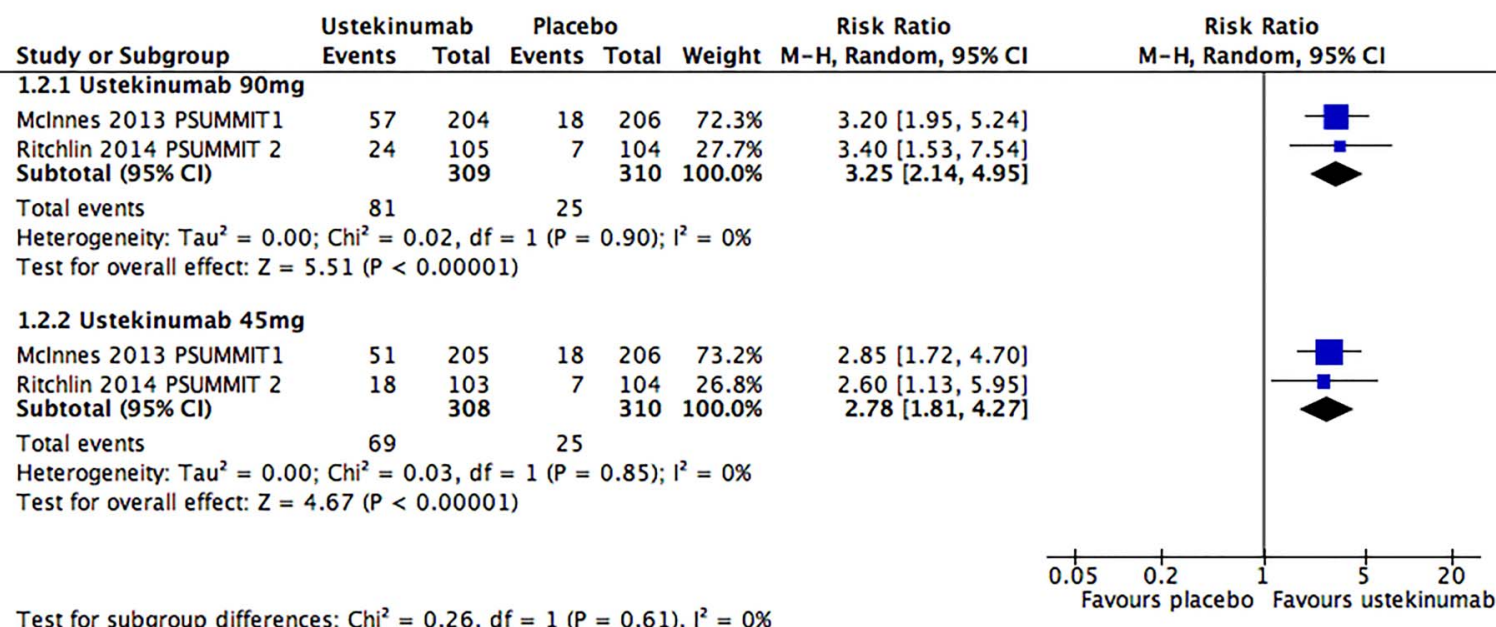

Test for subqroup differences: $\mathrm{Ch}^{2}=0.26, \mathrm{df}=1(\mathrm{P}=0.61), \mathrm{I}^{2}=0 \%$

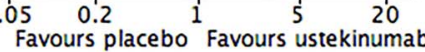

C

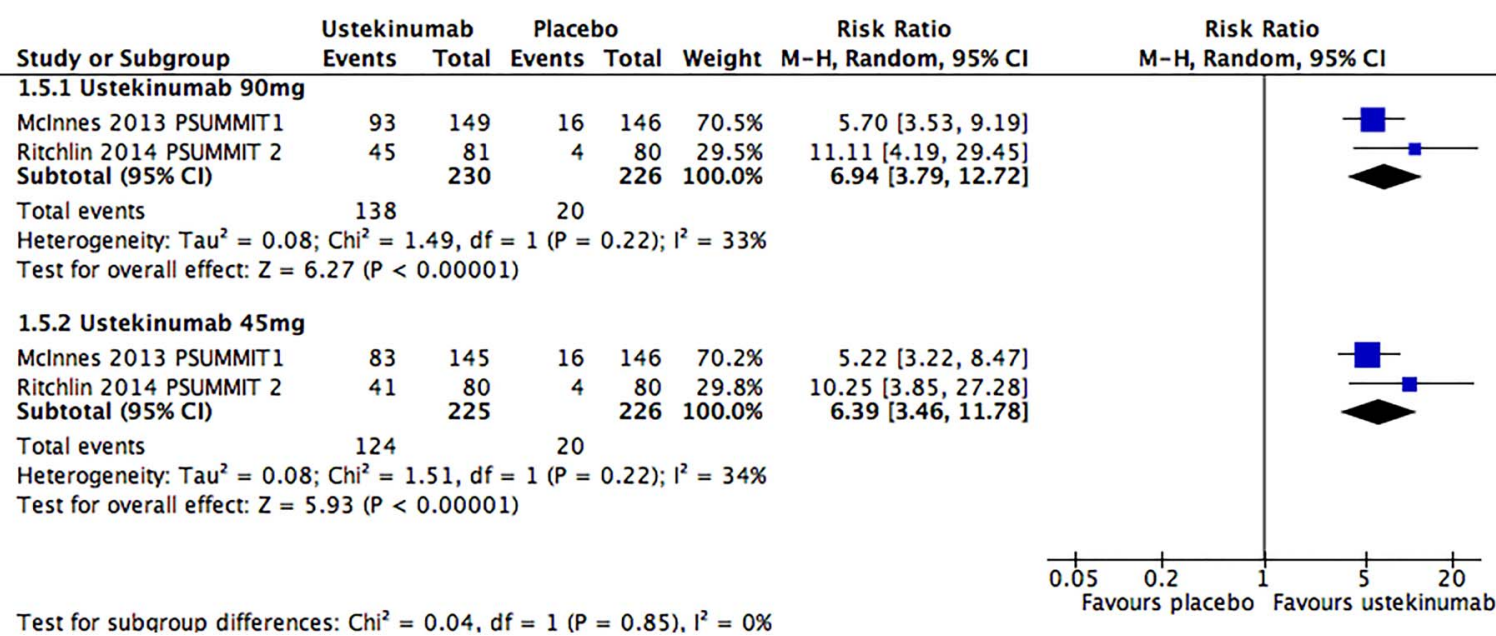

Figure 1 Main efficacy outcomes of ustekinumab at 24 weeks: (A) American College of Rheumatology 20\% improvement (ACR 20); (B) ACR 50; (C) Psoriasis Area Severity Index (PASI) 75.

the first step of the treatment algorithm), compared with $49 \%$ in the standard care arm.

\section{DISCUSSION}

This SLR summarises current data from RCTs for DMARDs in PsA. It reveals that two bDMARDs against new therapeutic targets, UST and SEC, and one new tsDMARD, APR, are efficacious for the treatment of PsA and have no major safety signals. Moreover, studies with new TNFis (golimumab and certolizumab pegol) confirm the efficacy of this class of drugs. Finally, one strategy trial indicates that treatment set to a therapeutic target achieves better outcome than non-targeted therapy in 
A

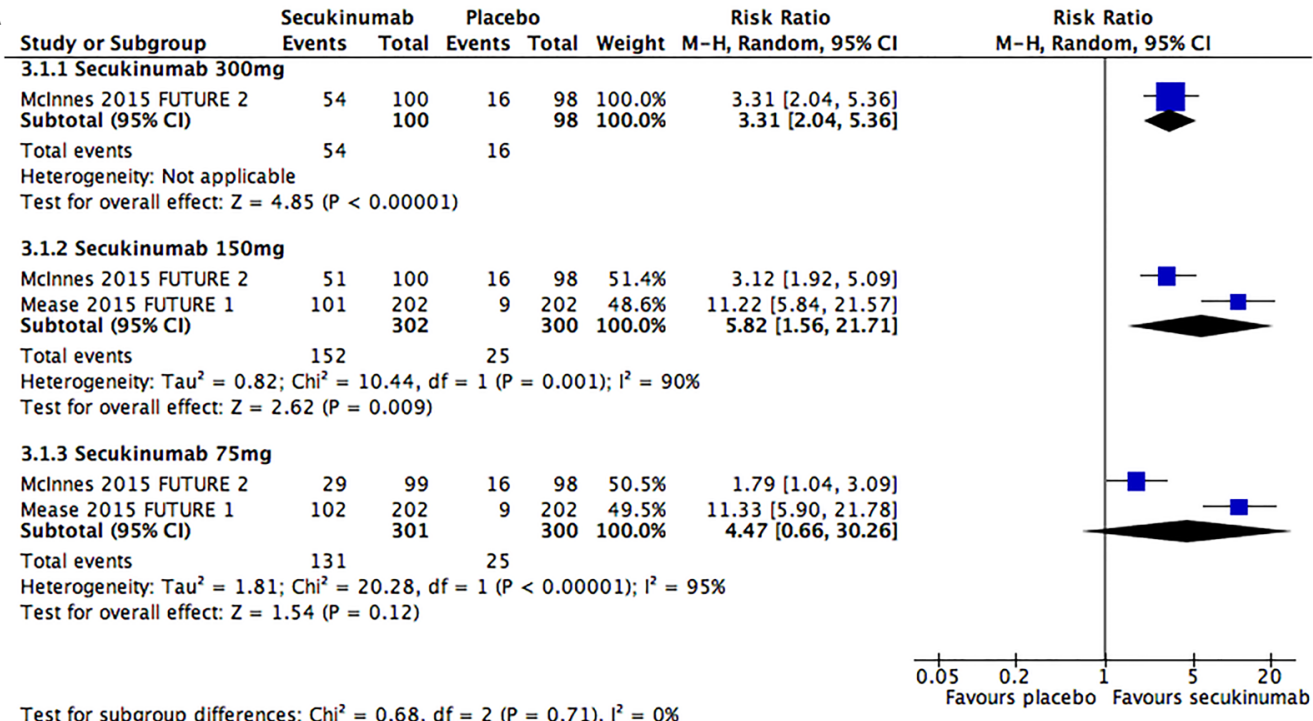

Test for subqroup differences: $\mathrm{Chi}^{2}=0.68, \mathrm{df}=2(\mathrm{P}=0.71), \mathrm{I}^{2}=0 \%$

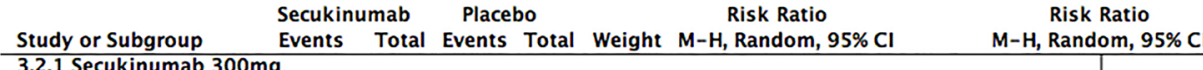

3.2 .1 Secukinumab $300 \mathrm{mg}$

$\begin{array}{lllllll}\text { McInnes 2015 FUTURE } 2 & 35 & 100 & 7 & 98 & 100.0 \% & 4.90[2.29,10.50\end{array}$

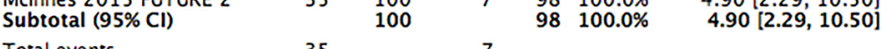

Total events

Test for overall effect: $Z=4.09(P<0.0001)$

3.2.2 Secukinumab $150 \mathrm{mg}$

\begin{tabular}{|c|c|c|c|c|c|c|}
\hline UTURE 2 & 35 & 100 & 7 & 98 & $32.0 \%$ & $4.90[2.29,10.50]$ \\
\hline $\begin{array}{l}\text { FUTURE } 1 \\
; \% \mathrm{CI})\end{array}$ & 70 & $\begin{array}{l}202 \\
302\end{array}$ & 15 & $\begin{array}{l}202 \\
300\end{array}$ & $\begin{array}{r}68.0 \% \\
100.0 \%\end{array}$ & $\begin{array}{r}4.67[2.77,7.8 \\
4.74[3.08,7.2\end{array}$ \\
\hline
\end{tabular}

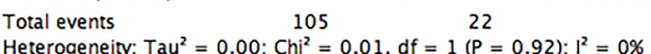

Test for overall effect: $Z=7.08(P<0.00001)$

3.2.3 Secukinumab $75 \mathrm{mg}$

McInnes 2015 FUTURE 2

Mease 2015 FUTURE 1
Subtotal $(95 \% \mathrm{CI})$

$\begin{array}{lllll}18 & 99 & 7 & 98 & 29.0 \%\end{array}$

$\begin{array}{rrrr}99 & 7 & 98 & 29.0 \% \\ 202 & 15 & 202 & 71.0 \% \\ 301 & & 300 & 100.0 \%\end{array}$

Heterogeneity: $\mathrm{Tau}^{2}=0.00 ; \mathrm{Chi}^{2}=0.94, \mathrm{df}=1 \stackrel{22}{(\mathrm{P}=0.33) ; l^{2}=0 \%}$

Test for overall effect: $Z=5.62(P<0.00001)$

Test for subqroup differences: $\mathrm{Chi}^{2}=0.93, \mathrm{df}=2(\mathrm{P}=0.63), \mathrm{I}^{2}=0 \%$

$2.55[1.11,5.82]$

$4.13[2.43,7.02]$
$3.59[2.30,5.61]$

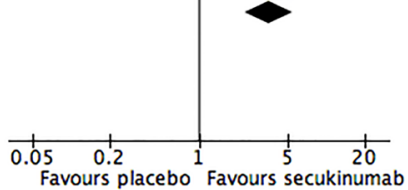

C

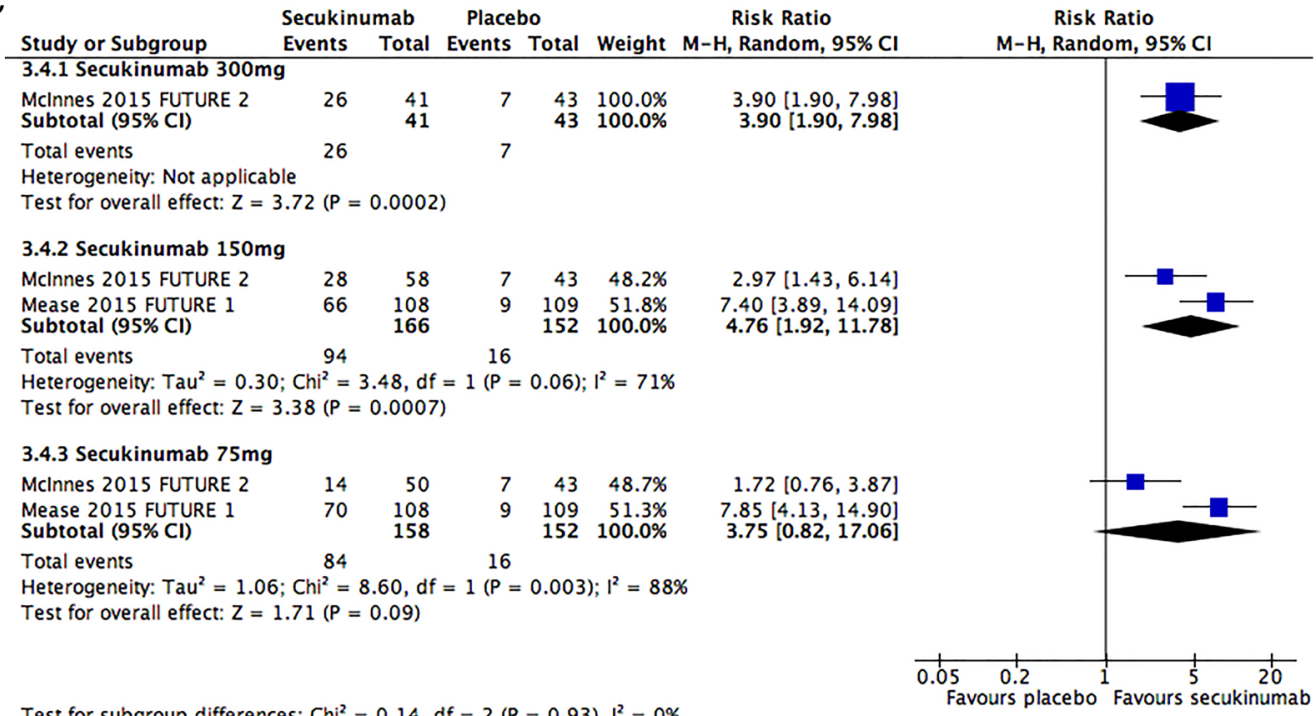

Figure 2 Main efficacy outcomes of secukinumab at 24 weeks: (A) American College of Rheumatology 20\% improvement (ACR 20); (B) ACR 50; (C) Psoriasis Area Severity Index (PASI) 75. 


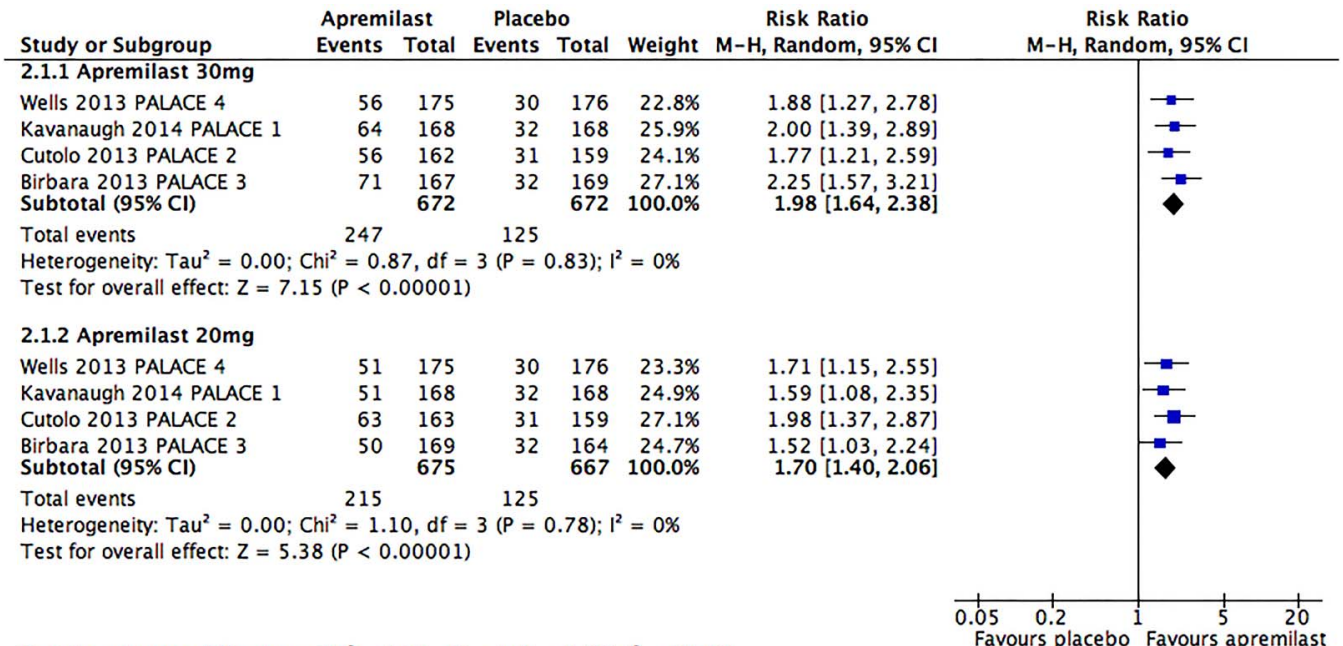

Test for subqroup differences: $\mathrm{Chi}^{2}=1.23, \mathrm{df}=1(\mathrm{P}=0.27), \mathrm{I}^{2}=18.5 \%$

Figure 3 Main efficacy outcomes of apremilast available at 16 weeks: American College of Rheumatology 20\% improvement (ACR 20). Most of these data were obtained from abstracts, were percentage of outcome achievement are reported, so the absolute figures had to be calculated for this review.

PsA, and indirectly shows efficacy of MTX in a high dose as this was the first step in the treatment algorithm.

UST, APR and SEC reflect the innovation in the treatment armamentarium of PsA. PBO-controlled trials have demonstrated their efficacy. However, in the absence of head-to-head studies, it is challenging to make accurate comparisons between the drugs, or between these agents and the already existing ones (eg, TNFi). The trial populations are different, for instance some of them included no TNFi-IR patients, others $<10 \%$ and others $>50 \%$, and these trials have also shown that patients who are TNFi-IR, though also responding to these drugs, have a numerically lower response. This and other aspects jeopardise comparison across the studies. Still suffering from these limitations, the calculation of NNT allows us to judge outcome achievement with one intervention taking the PBO response into account. We have found that responses from UST and SEC were numerically higher when compared with APR, and both on joint and especially on skin outcomes, as well as on dactylitis. Additionally, data on structural damage are currently lacking for APR; such data will be essential to learn about its potential disease modifying action. Regarding safety, these new compounds have also demonstrated safety on a short/medium term and no major safety issues have arisen. Some signals have been found, such as the occurrence of (mainly oral) candidiasis with SEC and diarrhoea with APR; while these did not lead to a higher proportion of withdrawals due to AEs in the active treatment arm, they warrant further information. Long-term safety data and data from daily clinical practice are needed, and with the licensing of these drugs, they are expected to be gathered during the upcoming years. Meanwhile, we can gain more insights into the safety of these new agents with the experience acquired in psoriasis, which is reassuring. ${ }^{46}$

This SLR also highlighted a known problem in trials with PsA: there is a lack of uniformity of outcomes reported and, especially, of the instruments chosen to address some of the outcomes. ${ }^{47}$ The PsA Working Group within Outcome Measures in Rheumatology (OMERACT) group has selected a core set of domains to be reported in trials. ${ }^{48}$ This core set does recommend specific instruments to be used to address each domain $^{47} 48$ but an update is ongoing and will hopefully provide clear guidance on the choice of instruments. ${ }^{49}$
Furthermore, in trials, the core set is not always assessed. ${ }^{47}$ In PsA, possibly due to additional lack of standardisation of instruments to address each of the outcomes, trials report several different outcome measures in particular for enthesitis and dactylitis (see online supplementary table S5). Harmonisation of outcomes assessments and instruments included in RCTs would be expected to improve the assessment of new treatment agents, and is therefore desirable.

An aspect that is common to almost all interventions evaluated is the lack of data on PsA patients with axial involvement. Trials have not specifically addressed this particular group of patients. This remains an unmet need, for which, until further resolution, likely the best alternative is to rely on data from patients with axial spondyloarthritis. ${ }^{50}$

The new studies with TNFi (golimumab and certolizumab pegol) have mainly been confirmatory for the class they belong to. One new aspect is that we now have data on the response to TNFi among TNFi-IR patients. These patients still respond to TNFi, namely certolizumab pegol, and in a similar proportion to TNFi-naive patients; while this appears to be different from respective observations in $\mathrm{RA}^{51}$ and may support switching within the same mechanism of action, namely between TNFis. ${ }^{22}$ However these results are based on only one trial in which this population only constituted a subset of patients studied; thus, more data are needed in this respect.

An important trial aiming at clarifying the role of MTX in PsA, the methotrexate in psoriatic arthritis (MIPA) trial, has been conducted. ${ }^{14}$ This was a low RoB trial, which could have shed more light on this question. MIPA, however, failed to reach its primary end point, which casts doubt on the role of MTX in PsA. But two important aspects cannot be ignored: (1) dosages of MTX used were lower (15 mg/week) than what is commonly used in clinical practice or was applied in the TICOPA trial (25 mg/week); (2) patients with $\geq 1$ SJC were included (actually the study population had a SJC ranging from 2 onwards), and the primary end point, PsARC, is based on a change in $\geq 30 \%$ in SJC, which may be difficult to achieve in patients with few swollen joints. Because of these methodological pitfalls, the interpretation of the MIPA results is difficult.

Lastly, TICOPA indicated that a more target-driven approach to treatment improves patient outcomes. ${ }^{44}$ This underlines the 
importance of treating patients towards a predefined therapeutic target. Given the fact that MTX at a dose of $25 \mathrm{mg}$ was the first step in the treatment algorithm used, this trial indirectly provides evidence that MTX is efficacious in PsA. At 48 weeks, a quarter of the patients were still on MTX monotherapy, which confirms its efficacy in this group of patients. This proportion is to be compared with half of the patients on MTX monotherapy in the standard care arm, in which rheumatologists were free to choose their patient's treatment. This challenges the findings from MIPA, pointing towards an efficacy of MTX in PsA (in appropriate doses) and emphasises the need for another trial to clarify the precise role of MTX in the treatment of PsA.

This systematic review has some limitations that need to be taken into account. The study selection and data extraction were performed by one reviewer only, whereas ideally this work should be undertaken by two people independently. In what concerns safety outcomes, where the long term is of particular importance, RCTs are not the best study type to provide the necessary answers. However, observational studies are only truly informative when they include sufficient patient numbers and the follow-up is of high quality; as such studies are currently very scarce in the PsA literature they were not analysed here. The risk of bias could not be assessed for all included studies when only the abstract was available. Strengths of this SLR are the methodological rigour with which it was conducted and the useful information it provides, for clinicians as well as for the task force responsible for updating the PsA treatment recommendations.

In conclusion, we have updated the evidence on efficacy and safety of pharmacological treatment of PsA. This review informs the update of the EULAR recommendations for the management of PsA.

\section{Author affiliations}

'Department of Rheumatology, Leiden University Medical Centre, Leiden, The Netherlands

${ }^{2}$ Division of Rheumatology, Department of Medicine, Medical University of Vienna, Hietzing Hospital, Vienna, Austria

${ }^{3}$ Department of Clinical Immunology \& Rheumatology, Amsterdam Rheumatology

Center, Amsterdam and Atrium Medical Center, Heerlen, The Netherlands

${ }^{4}$ Medicine Faculty, Paris Descartes University, Paris, France

${ }^{5}$ Rheumatology B Department, APHP, Cochin Hospital, Paris, France

${ }^{6}$ Leeds Institute of Rheumatic and Musculoskeletal Medicine, University of Leeds, Leeds, UK

${ }^{7}$ NIHR Leeds Musculoskeletal Biomedical Research Unit, Leeds Teaching Hospitals Trust, Leeds, UK

${ }^{8}$ EULAR past Vice President representing People with Arthritis/Rheumatism in Europe (PARE)

${ }^{9}$ Research Laboratory and Clinical Division of Rheumatology, Department of Internal Medicine, University of Genova, Italy

${ }^{10}$ Independent Nurse Consultant, North Devon, UK

${ }^{11}$ Sorbonne Universités, UPMC Univ Paris 06, Institut Pierre Louis d'Epidémiologie et de Santé Publique, GRC-UPMC 08 (EEMOIS), Paris, France

${ }^{12}$ Department of rheumatology, AP-HP, Pitié Salpêtrière Hospital, Paris, France

Acknowledgements The authors thank Louise Falzon, librarian at the Center for Behavioral Cardiovascular Health, Columbia University Medical Center, New York and former Trial Search Coordinator from the Cochrane Musculoskeletal Group, for assisting with the design of the search strategy.

Competing interests The authors declare a potential conflict of interest having received grant support and/or honoraria for consultations and/or for presentations as indicated. ISS: Amgen, Abbvie, Astra-Zeneca, Astro, BMS, Celgene, Glaxo, ILTOO, Janssen, Merck-Serono, MSD, Novartis-Sandoz, Pfizer, Roche-Chugai, Samsung, UCB. RL: AbbVie, Ablynx, Amgen, Astra-Zeneca, Bristol Myers Squibb, Celgene, Galapagos, Janssen (formerly Centocor), Glaxo-Smith-Kline, Novartis, Novo-Nordisk, Merck, Pfizer, Roche, Schering-Plough, TiGenix, UCB, Wyeth. Director of Rheumatology Consultancy BV. DvdH: Consulting fees and/or research grants from AbbVie, Amgen, Astellas, AstraZeneca, Augurex, BMS, Boehringer Ingelheim, Celgene, Centocor, Chugai, Covagen, Daiichi, Eli-Lilly, Galapagos, GSK, Janssen Biologics, Merck, Novartis, Novo-Nordisk, Otsuka, Pfizer, Roche, Sanofi-Aventis,
UCB, Vertex. Director of Imaging Rheumatology bv. MD: Abbvie, Novartis, Pfizer, Lilly, UCB. PE Abbvie, BMS, MSD, Novartis-Sandoz, Pfizer, Roche-Chugai, Samsung, UCB. MdW: AbbVie, BMS, Eli-Lilly, Roche. MCC, Celltrion, BMS, Abbvie, Actelion, Mundipharm, Horizon, Pfizer, Novartis, Boehringer, SO: AbbVie, Hospira, MSD. LG: Abbvie, Celgene, Chugai, Janssen, MSD, Novartis, Pfizer, Roche, Sanofi-Aventis, UCB.

Provenance and peer review Not commissioned; externally peer reviewed.

\section{REFERENCES}

1 McInnes IB, Kavanaugh A, Gottlieb AB, et al. Efficacy and safety of ustekinumab in patients with active psoriatic arthritis: 1 year results of the phase 3, multicentre, double-blind, placebo-controlled PSUMMIT 1 trial. Lancet 2013;382:780-9.

2 Ritchlin C, Rahman P, Kavanaugh A, et al. Efficacy and safety of the anti-IL-12/23 p40 monoclonal antibody, ustekinumab, in patients with active psoriatic arthritis despite conventional non-biological and biological anti-tumour necrosis factor therapy: 6-month and 1-year results of the phase 3, multicentre, double-blind, placebo-controlled, randomised PSUMMIT 2 trial. Ann Rheum Dis 2014;73:990-9.

3 Kavanaugh A, Mease PJ, Gomez-Reino JJ, et al. Treatment of psoriatic arthritis in a phase 3 randomised, placebo-controlled trial with apremilast, an oral phosphodiesterase 4 inhibitor. Ann Rheum Dis 2014;73:1020-6.

4 McInnes IB, Mease PJ, Kirkham B, et al. Secukinumab, a human anti-interleukin-17A monoclonal antibody, in patients with psoriatic arthritis (FUTURE 2): a randomised, double-blind, placebo-controlled, phase 3 trial. Lancet 2015;386:1137-46.

5 Mease PJ, McInnes IB, Kirkham B, et al. Secukinumab Inhibition of Interleukin-17A in Patients with Psoriatic Arthritis. N Engl J Med 2015;373:1329-39.

6 Gossec L, Smolen JS, Gaujoux-Viala C, et al. European League Against Rheumatism recommendations for the management of psoriatic arthritis with pharmacological therapies. Ann Rheum Dis 2012;71:4-12.

7 Smolen JS, Ramiro S, et al. European League Against Rheumatism (EULAR) recommendations for the management of psoriatic arthritis with pharmacological therapies: 2015 update. Ann Rheum Dis 2016;75:499-510.

8 Ash Z, Gaujoux-Viala C, Gossec L, et al. A systematic literature review of drug therapies for the treatment of psoriatic arthritis: current evidence and meta-analysis informing the EULAR recommendations for the management of psoriatic arthritis. Ann Rheum Dis 2012;71:319-26.

9 Sackett D, WS R, Rosenberg W, et al. Evidence-based medicine: how to practice and teach EBM. London: Churchill Livingstone, 1997.

10 Smolen JS, van der Heijde D, Machold KP, et al. Proposal for a new nomenclature of disease-modifying antirheumatic drugs. Ann Rheum Dis 2014;73:3-5.

11 Coates LC, Fransen J, Helliwell PS. Defining minimal disease activity in psoriatic arthritis: a proposed objective target for treatment. Ann Rheum Dis 2010:69:48-53.

12 Higgins J, Altman DA. Assessing risk of bias in included studies. In: Higgins JPT, Green S, eds. Cochrane handbook for systematic reviews of interventions. Chapter 8. The Cochrane Collaboration, 2008.

13 Deeks JH, Altman D. Analysing data and undertaking meta-analyses: Cochrane handbook for systematic reviews of interventions version 5.1.0 [updated March 2011]. The Cochrane Collaboration, 2011.

14 Kingsley GH, Kowalczyk A, Taylor $\mathrm{H}$, et al. A randomized placebo-controlled trial of methotrexate in psoriatic arthritis. Rheumatology (Oxford) 2012;51:1368-77.

15 Atzeni F, Boccassini L, Antivalle M, et al. Etanercept plus ciclosporin versus etanercept plus methotrexate for maintaining clinical control over psoriatic arthritis: a randomised pilot study. Ann Rheum Dis 2011;70:712-14.

16 Asaduzzaman ATM, Sikder A, Mahmud MM, et al. Efficacy and safety of leflunomide in psoriatic arthritis. J Pakistan Assoc Dermatol 2014;24:51-6.

17 Kavanaugh A, van der Heijde D, Mclnnes IB, et al. Golimumab in psoriatic arthritis: one-year clinical efficacy, radiographic, and safety results from a phase III, randomized, placebo-controlled trial. Arthritis Rheum 2012;64:2504-17.

18 Kavanaugh A, Mease P. Treatment of psoriatic arthritis with tumor necrosis factor inhibitors: longer-term outcomes including enthesitis and dactylitis with golimumab treatment in the Longterm Extension of a Randomized, Placebo-controlled Study (GO-REVEAL). J Rheumatol Supp/ 2012;89:90-3.

19 Kavanaugh A, McInnes IB, Krueger GG, et al. Patient-reported outcomes and the association with clinical response in patients with active psoriatic arthritis treated with golimumab: findings through 2 years of a phase III, multicenter, randomized, double-blind, placebo-controlled trial. Arthritis Care Res (Hoboken) 2013:65:1666-73.

20 Kavanaugh A, McInnes IB, Mease PJ, et al. Clinical efficacy, radiographic and safety findings through 2 years of golimumab treatment in patients with active psoriatic arthritis: results from a long-term extension of the randomised, placebo-controlled GO-REVEAL study. Ann Rheum Dis 2013;72:1777-85.

21 Kavanaugh A, McInnes IB, Mease P, et al. Clinical efficacy, radiographic and safety findings through 5 years of subcutaneous golimumab treatment in patients with active psoriatic arthritis: results from a long-term extension of a randomised, placebo-controlled trial (the GO-REVEAL study). Ann Rheum Dis 2014;73:1689-94. 
22 Mease PJ, Fleischmann R, Deodhar AA, et al. Effect of certolizumab pegol on signs and symptoms in patients with psoriatic arthritis: 24-week results of a Phase 3 double-blind randomised placebo-controlled study (RAPID-PsA). Ann Rheum Dis 2014;73:48-55.

23 Gladman D, Fleischmann R, Coteur G, et al. Effect of certolizumab pegol on multiple facets of psoriatic arthritis as reported by patients: 24-week patient-reported outcome results of a phase III, multicenter study. Arthritis Care Res (Hoboken) 2014:66:1085-92.

24 van der Heijde D, Fleischmann R, Wollenhaupt J, et al. Effect of different imputation approaches on the evaluation of radiographic progression in patients with psoriatic arthritis: results of the RAPID-PSA 24-week phase III double-blind randomised placebo-controlled study of certolizumab pegol. Ann Rheum Dis 2014;73:233-7.

25 Kavanaugh A, Gladman D, van der Heijde D, et al. Improvements in productivity at paid work and within the household, and increased participation in daily activities after 24 weeks of certolizumab pegol treatment of patients with psoriatic arthritis: results of a phase 3 double-blind randomised placebo-controlled study. Ann Rheum Dis 2015;74:44-51.

26 Kavanaugh A, Gladman D, van der Heijde D. Reduction of disease burden on workplace and household productivity in psoriatic arthritis over 48 weeks of treatment with certolizumab pegol. Arthritis Rheum 2013;65(Suppl 10):326.

27 Kavanaugh A, Gladman D, van der Heijde D. Sustained improvements in workplace and household productivity and social participation with certolizumab pegol over 96 weeks in patients with psoriatic arthritis. Arthritis Rheum 2014;66(Suppl 10):1552.

28 Baranauskaite A, Raffayová H, Kungurov NV, et al. Infliximab plus methotrexate is superior to methotrexate alone in the treatment of psoriatic arthritis in methotrexate-naive patients: the RESPOND study. Ann Rheum Dis 2012;71:541-8.

29 Mease PJ, Heckaman M, Kary S, et al. Application and modifications of minimal disease activity measures for patients with psoriatic arthritis treated with adalimumab: subanalyses of ADEPT. J Rheumatol 2013;40:647-52.

30 Sterry W, Ortonne J-P, Kirkham B, et al. Comparison of two etanercept regimens for treatment of psoriasis and psoriatic arthritis: PRESTA randomised double blind multicentre trial. BMJ 2010;340:C147.

31 Prinz JC, Fitzgerald O, Boggs RI, et al. Combination of skin, joint and quality of life outcomes with etanercept in psoriasis and psoriatic arthritis in the PRESTA trial. J Eur Acad Dermatol Venereol 2011;25:559-64.

32 Gniadecki R, Robertson D, Molta CT, et al. Self-reported health outcomes in patients with psoriasis and psoriatic arthritis randomized to two etanercept regimens. J Eur Acad Dermatol Venereol 2012;26:1436-43.

33 Boggs RL, Karpáti S, Li W, et al. Employment is maintained and sick days decreased in psoriasis/psoriatic arthritis patients with etanercept treatment. BMC Dermatol 2014;14:14.

34 Kavanaugh A, Ritchlin C, Rahman P, et al. Ustekinumab, an anti-IL-12/23 p40 monoclonal antibody, inhibits radiographic progression in patients with active psoriatic arthritis: results of an integrated analysis of radiographic data from the phase 3, multicentre, randomised, double-blind, placebo-controlled PSUMMIT-1 and PSUMMIT-2 trials. Ann Rheum Dis 2014;73:1000-6.

35 Zhang F, Tencer T, Li S. Work productivity improvement associated with apremilast, an oral phosphodiesterase 4 inhibitor, in patients with psoriatic arthritis: results of a phase 3, randomized, controlled trial. Arthritis Rheum 2014;66(Suppl 10):1597.

36 Kavanaugh A, Adebajo AO, Gladman DD. Apremilast, an Oral Phosphodiesterase 4 Inhibitor, Is Associated with Long-Term (104-Week) Improvements in Patients with
Psoriatic Arthritis: Results from a Phase 3, Randomized, Controlled Trial. Arthritis Rheum 2014;66(Suppl 10):1590.

37 Mease PJ, Adebajo AO, Gladman DD. Long-Term (104-Week) Safety Profile of Apremilast, an Oral Phosphodiesterase 4 Inhibitor, in Patients with Psoriatic Arthritis: Results from a Phase 3, Randomized, Controlled Trial and Open-Label Extension. Arthritis Rheum 2014;66(Suppl 10):1564.

38 Cutolo M, Myerson G, Fleischmann R. Long-term (52-week) results of a phase 3, randomized, controlled trial of apremilast, an oral phosphodiesterase 4 inhibitor, in patients with psoriatic arthritis (PALACE 2). Arthritis Rheum 2013;65 (Suppl 10):815.

39 Edwards C, Blanco FJ, Crowley J. Long-term (52-week) results of a phase 3, randomized, controlled trial of apremilast, an oral phosphodiesterase 4 inhibitor, in patients with psoriatic arthritis and current skin involvement (PALACE 3). Arthritis Rheum 2013;65(Suppl 10):311.

40 Wells A, Edwards C, Adebajo AO. Apremilast in the treatment of DMARD-Naïve psoriatic arthritis patients: results of a phase 3 randomized, controlled trial (PALACE 4). Arthritis Rheum 2013;65(Suppl 10):L4.

41 Wells A, Aelion JA, Adebajo AO. A phase 3, randomized, controlled trial of apremilast, an oral phosphodiesterase 4 inhibitor, for treatment of psoriatic arthritis: long-term (52-week) improvements in physical function. Arthritis Rheum 2014;66 (Suppl 10):602.

42 Adebajo AO, Wells A, Edwards C. Long-term safety and tolerabiility of apremilast, an oral phosphodiesterase 4 inhibitor, in patients with psoriatic arthritis: a phase 3 , randomized, controlled trial. Ann Rheum Dis 2014;73(Suppl 2):730.

43 Wells A, Edwards C, Adebajo AO. Long-term (104-week) safety and efficacy of monotherapy with apremilast in dmard-naïve patients with psoriatic arthritis: a phase 3, randomized, controlled trial and open-label extension (PALACE 4). Arthritis Rheum 2014;66(Suppl 10):L22.

44 Coates LC, Moverley AR, McParland L, et al. Effect of tight control of inflammation in early psoriatic arthritis (TICOPA): a UK multicentre, open-label, randomised controlled trial. Lancet 2015. doi: 10.1016/S0140-6736(15)00347-5. [Epub ahead of print 30 Sep 2015].

45 Kavanaugh A, Puig L, Gottlieb AB. Efficacy and safety of ustekinumab in patients with active psoriatic arthritis: 2-year results from a phase 3, multicenter, double-blind, placebo-controlled study. Arthritis Rheum 2013;65(Suppl 10):L10.

46 Papp K, Gottlieb AB, Naldi L, et al. Safety surveillance for ustekinumab and other psoriasis treatments from the Psoriasis Longitudinal Assessment and Registry (PSOLAR). J Drugs Dermatol 2015;14:706-14.

47 Palominos PE, Gaujoux-Viala C, Fautrel B, et al. Clinical outcomes in psoriatic arthritis: A systematic literature review. Arthritis Care Res (Hoboken) 2012;64:397-406.

48 Gladman DD, Mease PJ, Strand V, et al. Consensus on a core set of domains for psoriatic arthritis. J Rheumatol 2007;34:1167-70.

49 Tillett W, Eder L, Goel N, et al. Enhanced patient involvement and the need to revise the core set-report from the psoriatic arthritis working group at OMERACT 2014. J Rheumatol 2015;42:2198-203.

50 van der Heijde D, Sieper J, Maksymowych WP, et al. 2010 Update of the international ASAS recommendations for the use of anti-TNF agents in patients with axial spondyloarthritis. Ann Rheum Dis 2011;70:905-8.

51 Smolen JS, Weinblatt ME. When patients with rheumatoid arthritis fail tumour necrosis factor inhibitors: what is the next step? Ann Rheum Dis 2008; $67: 1497-8$ 